\title{
Retraction note to: Nutritional evaluation of wheat straw treated with Crinipellis sp. in Sahiwal calves
}

\author{
Munnurpal Satyanarayana Mahesh • Madhu Mohini • \\ Pankaj Jha $\cdot$ Sanjay Pandurang Sawant • \\ Shivlal Singh Kundu • Ramesh Chander Kuhad
}

Published online: 3 January 2014

(C) Springer Science+Business Media Dordrecht 2014

\section{Retraction to: Trop Anim Health Prod}

DOI 10.1007/s11250-013-0440-1

The authors hereby retract the article entitled "Nutritional evaluation of wheat straw treated with Crinipellis sp. in Sahiwal calves" (Mahesh et al. 2013) previously published online first in Tropical Animal Health and Production as they had no permission to use the data presented in the Table 1, for publication.

\section{Reference}

Mahesh, M.S., Mohini, M., Jha, P., Sawant, S.P., Kundu, S.S., Kuhad, R.C., 2013. Nutritional evaluation of wheat straw treated with Crinipellis sp. in Sahiwal calves. Tropical Animal Health and Production. DOI: 10.1007/s11250-013-0440-1, published in Vol. 45, issue 8, pp 1817-1823, 2013.

The online version of the original article can be found at http://dx.doi.org/ 10.1007/s11250-013-0440-1.

M. S. Mahesh $(\varangle) \cdot$ M. Mohini $\cdot$ P. Jha $\cdot$ S. P. Sawant $\cdot$ S. S. Kundu Dairy Cattle Nutrition Division, National Dairy Research Institute, Deemed University, Karnal, Haryana 132001, India

e-mail:drmaheshmsvet@gmail.com

R. C. Kuhad

Lignocellulose Biotechnology Laboratory, Department of

Microbiology, University of Delhi South Campus,

New Delhi 110021, India 